\title{
The Particle Size Dependence of CO Oxidation on Model Planar Titania Supported Gold Catalysts Measured by Parallel Thermographic Imaging.
}

\author{
Jovine Emmanuel, Brian E. Hayden* and Jaffar Saleh-Subaie \\ Chemistry, University of Southampton, Southampton SO17 1BJ, United Kingdom.
}

Keywords: gold, titania, particles, CO oxidation, thermography, high-throughput

\begin{abstract}
A parallel thermographic screening methodology has been developed which allows the measurements of the particle size and support influences on model planar heterogeneous catalysts. A screening chip was designed and fabricated in order to produce multiple fields of low stress silicon nitride membranes that exhibit low thermal conductivity and heat capacity. The heat generated on supported model catalysts in an exothermic reaction on the membranes was measured using a thermal (infra-red) imaging camera, which in turn provided a measure of the turn over frequency (TOF) for the reaction. The catalytic activity for CO oxidation on titania supported gold model catalysts with varying particle size has been measured on 100 catalysts simultaneously. The reaction has been investigated at $80^{\circ} \mathrm{C}$ and $170{ }^{\circ} \mathrm{C}$, and pressures ranging between 0.06 mbar and 1.5 mbar for various $\mathrm{O}_{2}$ :CO ratios. Under all conditions investigated, a monotonic increase in the TOF is observed with decreasing particle diameter (d) which is proportional to ca. $d^{-1.8}$ in the range $6>\mathrm{d} / \mathrm{nm}>1.5$. This is in the opposite direction to the number of potentially active perimeter sites which increases linearly with increasing particle size on these catalysts. We show that the surface area specific activity of the gold is increasing even more steeply with reduced particle size, and is proportional to ca. $\mathrm{d}^{-4}$. This rate of increase in activity is significantly higher than one would expect by any increase one may expect as a result of more active low co-ordinate sites on the gold. The steep increase in activity is ascribed to an electronic interaction between the substrate and the particle.
\end{abstract}

\footnotetext{
* Corresponding author
} 


\section{Introduction}

The activity of supported metal heterogeneous catalysts is generally strongly dependent on the support, and the morphology and size of the supported metal particles. Systematic studies of the activity of well characterised supported metal catalysts under identical reaction conditions are therefore important in understanding the effects of particle size and support. An excellent example of a heterogeneous catalyst exhibiting a strong support and particle size effect on activity is titania supported gold in the low temperature oxidation of small molecules such as $\mathrm{CO}$ and hydrocarbons.

Although it had been shown in 1973 that olefin hydrogenation was catalysed by supported $\mathrm{Au}$ by Bond et al. ${ }^{1}$ it was not until the work by Haruta et al. ${ }^{2}$ in 1987 which revealed that gold nanoparticles highly dispersed on reducible metal oxides had extraordinary activity in catalysing the oxidation of $\mathrm{CO}$ even at low temperatures. Gold nanoparticles supported on reducible metal oxides have also been shown to catalyse a number of other reactions including the water gas shift, selective hydrogenation of hydrocarbons, hydrochlorination, and selective epoxidation. ${ }^{3}$ Experimental studies show ${ }^{4}$ that small particles of gold, typically less than $5 \mathrm{~nm}$, are active toward $\mathrm{CO}$ oxidation even at temperatures far below $25^{\circ} \mathrm{C}$. Indeed, high activity for $\mathrm{CO}$ oxidation on titania supported Au has been observed at temperatures as low as $120 \mathrm{~K} .{ }^{5}$ A monotonic increase in the TOF for $\mathrm{CO}$ oxidation on titania supported Au has been observed down to ca. $3 \mathrm{~nm}$ diameter particles, ${ }^{6-7}$ and $2 \mathrm{~nm}$ particles ${ }^{8}$ while in studies down to the lower particle sizes evidence a maximum in the TOF at $2.5-3 \mathrm{~nm} \cdot{ }^{9-11}$ The active site responsible for the enhanced activity of gold nano-particles on titania and other reducible oxides is the subject of considerable debate, ${ }^{12}$ but whatever the mechanism of enhancement it should be consistent with the observed particle size dependence of the reaction. The electro-oxidation of $\mathrm{CO}$ on model titania supported gold catalysts in acid electrolyte has also been measured using highthroughput methods, and evidenced a strong activation of gold particles by the support and a particle sized dependence with maximum activity observed at a diameter of $3 \mathrm{~nm} .{ }^{13}$

While the combinatorial synthesis of well characterised model oxide supported metal particle electrocatalysts allowed the screening of a number of electrochemical reactions on various supports employing a high throughput electrochemical chip, the application of a high throughput screen for the heterogeneous reaction is more challenging. An elegant approach suitable for thin film low area alloy catalysts has been demonstrated for the case of the $\mathrm{H}_{2}-\mathrm{D}_{2}$ exchange reaction employing a 100 channel micro-reactor array and mass spectroscopy. ${ }^{14}$ For simple reactions where it is less important to be able to determine selectivity, net activity determined in an exothermic reaction using high throughput infrared thermography technique is attractive. This has been achieved for the screening of catalysts in the oxidation of hydrogen ${ }^{15}$ and octane $^{16}$, in both cases on high area catalyst samples. The challenge, however, is the extension of the technique to arrays of well characterised model catalysts, such as the metal supported electro-catalysts, ${ }^{17}$ to obtain structure / activity relationships: The significantly lower surface area of these planar catalysts requires an increased sensitivity in order to detect the heat generated during reaction. To this end, we report here the application of a micro-fabricated substrate which allows the high throughput measurement of a series of titania supported gold catalysts where the particle size has been controlled, allowing the particle size dependence of the reaction to be measured simultaneously in an identical gas phase environment. 


\section{Experimental}

Combinatorial synthesis of titania supported gold particles, with varying metal particle size, has been achieved using the evaporative methods described in detail elsewhere. ${ }^{18-19}$ The thin film synthesis chamber employed incorporated 3 electron-guns (Temescal) and 3 Knudsen cells (DCA) evaporation sources, and the operational base pressure was $1 \times 10^{-9}$ Torr. The titania (99.995\%, Alfa Aesar metals) and the gold (95.95\%, Goodfellow) were evaporated from electron-gun sources. Oxygen atoms generated from a plasma-atom source (1sccm oxygen at $300 \mathrm{~W}$ RF power) was used with evaporating titania to synthesise stoichiometric titania thin films (ca. $200 \mathrm{~nm}$ ) at a deposition rate of $4 \AA / \mathrm{s}$. The substrate was at ca. $50^{\circ} \mathrm{C}$ during deposition producing the amorphous titania phase. Film thickness was determined by measuring the step at the edge of a masked sample using tapping mode AFM (Vecco Autoprobe M5 $5 \mathrm{Nm}^{-1}$ silicon cantilever at $180 \mathrm{kHz}$ ). Particle size distributions have been determined using TEM (Jeol 3010 , accelerating voltage of $300 \mathrm{kV}$ ): ${ }^{19}$ A thin layer of titanium dioxide (using the same conditions as for the screening substrates) $15 \mathrm{~nm}$ to $25 \mathrm{~nm}$ thick was deposited onto Formvar ${ }^{\circledR}$ carbon coated copper TEM grids (Agar scientific) onto which the gold nanoparticles were deposited. The rate of gold deposition $\left(0.15 \AA \mathrm{s}^{-1}\right)$ was determined with the synthesis of continuous gold thin films, and short deposition times (30s - 360s) used to produce the Au particles through nucleation and growth on the titania substrates at ca. $250^{\circ} \mathrm{C}$. A moveable shutter was used to create variation in total flux of gold in order to produce various effective thicknesses of gold, and hence different particle sizes, across the substrate ${ }^{20}$ XPS measurements were undertaken in a UHV system incorporating a twin anode X-ray source ( $\mathrm{Mg} \mathrm{K \alpha}$ and $\mathrm{Al} \mathrm{K \alpha}$ ), and a VG Clam Single Channel XPS system analyser.

A silicon screening chip with an overall dimension of $35 \mathrm{~mm} \times 35 \mathrm{~mm}$ was micro-fabricated (450 $\mu \mathrm{m}$ thick silicon wafer) for the high throughput infrared thermography measurements. An array of $10 \times 10$ silicon nitride membranes $(1.5 \mathrm{~mm} \times 1.5 \mathrm{~mm})$ of thickness $600 \mathrm{~nm}$ were created by back etching the silicon to a layer of LP-CVD silicon nitride. A schematic of a single back etched field is shown in Figure 1 together with a top view of an actual screening chip.
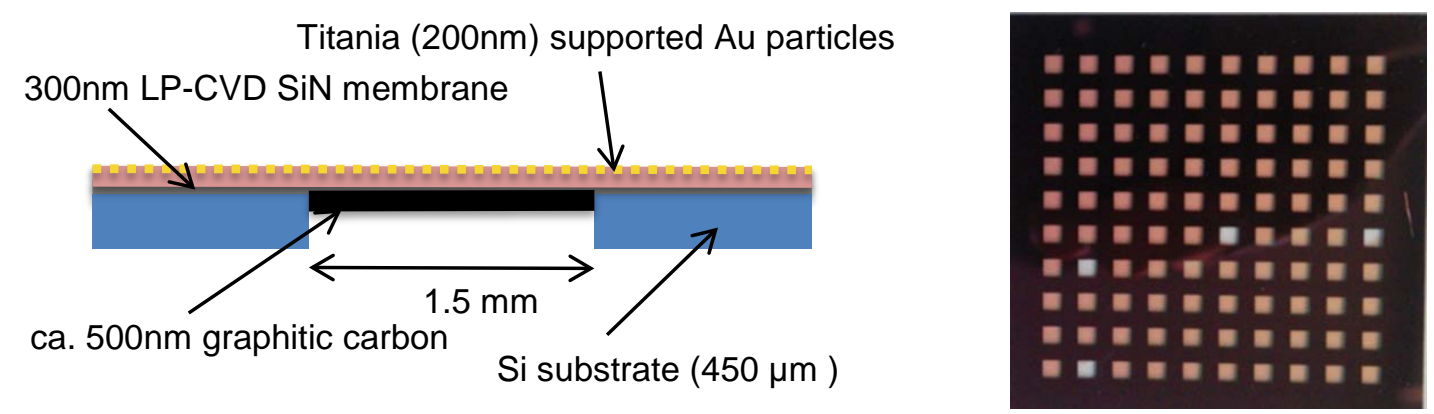

Figure $1 \mathrm{~A}$ schematic of a single field of the thermographic imaging screening chip together with an optical top down picture of complete chip: A number of the membranes have broken in this chip. The overall size of the chip is $35 \mathrm{~mm} \times 35 \mathrm{~mm}$.

The membrane, even with the $200 \mathrm{~nm}$ of titania supported catalyst, was optically transparent. In order to measure the temperature of the membrane, a thin graphitic carbon layer (ca. 
200nm) was deposited on the back of the membrane providing an emissivity close to that of a black body. The objective of the thin SiN membrane was to provide a support for the catalyst which had a small thermal mass and minimal thermal conductivity to the surrounding silicon chip: Heat generated during reaction on the catalyst would therefore raise the temperature of the membrane. The screening chip (Figure 1), with the catalyst synthesised over the complete chip, was mounted in a heated sample holder with a heat shield which allowed the complete chip to be heated homogeneously to a base temperature for reaction of up to ca. $250^{\circ} \mathrm{C}$. The sample holder was mounted in a UHV chamber incorporating an IR transparent window $\left(\mathrm{CaF}_{2}\right)$ and the surface of the chip imaged $(50 \mathrm{~mm}$ focal length camera lens) using a thermal camera (Jade III, CEDIP) operating in the spectral range of 3.6 to $5.1 \mu \mathrm{m}$ with a thermal sensitivity of ca. $20 \mathrm{mK}$. The spatial resolution of the camera was $320 \times 240$ pixels, and the complete $10 \mathrm{x}$ 10 array was imaged to fill the detector.

The reactions themselves were carried out in a turbomolecular pumped ultra-high vacuum chamber with a base pressure of $1 \times 10^{-10} \mathrm{mBar}$. The screening chip was mounted on a copper plate on a ceramic heater block incorporating nichrome heating wire: The holder was partly surrounded by a heat shield to ensure an even temperature across the sample. Reactions were carried out with a dynamic flow of gas through the chamber.

The temperature response of the catalyst on the membrane for a given power input (from an exothermic reaction) was calculated through finite element thermal modelling (Comsol Multiphisics ${ }^{\circledR}$ ). The assumption was that the energy loss over the membrane would be through conduction through the membrane (together with the titania support and the graphite layer) to the supporting silicon chip. Radiative and convective losses were assumed to be zero: additional radiative and convective losses over a few degrees temperature over the base temperature of reaction would be expected to be very small. For the $\mathrm{CO}$ oxidation reaction $\left(\Delta \mathrm{H}=-283 \mathrm{kJmol}^{-1}\right)^{21}$ for a pressure of $1 \times 10^{-3} \mathrm{mBar}$, assuming every molecule reacts, the theoretical power is $2.289 \times 10^{-4} \mathrm{Js}^{-1} \mathrm{~mm}^{-2}$. This results in a calculated temperature rise at the centre of the membrane, $\Delta \mathrm{T}=4^{\circ} \mathrm{C}$. The calculated sensitivity of the chip was used to calculate the TOF of reaction at the surface: the error associated with the absolute value of the TOF were estimate to be ca. $+/-30 \%$ mainly because of uncertainties in the thermal conductivity values for the membrane composite layer. A simulation of the temperature distribution across the $1.5 \mathrm{~mm} \times 1.5 \mathrm{~mm}$ membrane is shown in Figure $2 \mathrm{~A}$ and $2 \mathrm{~B}$. Figure $2 \mathrm{C}$ shows a typical averaged thermal image of a single membrane. The image is averaged in a 10x10 matrix over the complete membrane, but only the central $6 \times 6$ matrix is averaged to obtain the temperature rise associated with the reaction. These averaging over this $6 \times 6$ matrix corresponds to $90 \%$ of $\Delta \mathrm{T}$ maximum. 


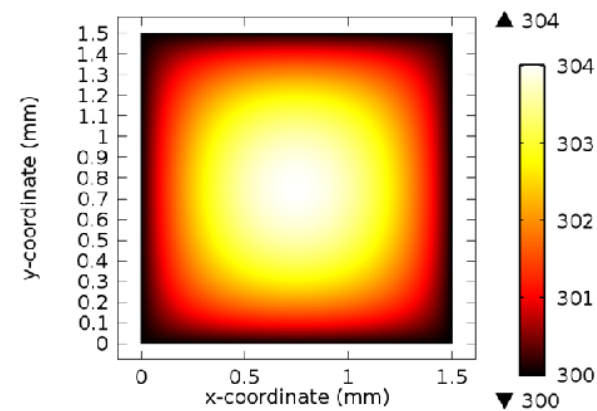

A

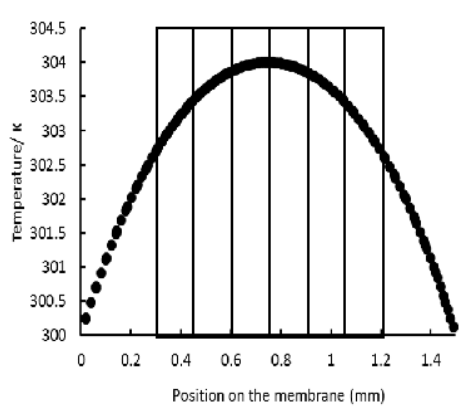

B

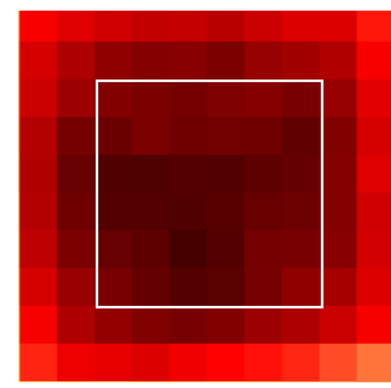

C

Figure $2(A)$ The simulated temperature distribution of a single $1.5 \mathrm{~mm} \times 1.5 \mathrm{~mm}, 600 \mathrm{~nm}$ membrane for the $\mathrm{CO}$ oxidation reaction $\left(\Delta \mathrm{H}=-283 \mathrm{kJmol}^{-1}\right)^{21}$ for a CO pressure of $1 \times 10^{-3} \mathrm{mBar}$, and assuming every molecule reacts: The theoretical reaction power is $2.289 \times 10^{-4} \mathrm{Js}^{-1} \mathrm{~mm}^{-2}$. The base temperature of the chip is $300^{\circ} \mathrm{C}$. (B) The calculated temperature variation across the centre of the membrane. The 6 marked regions across the distribution correspond the regions averaged in the central $6 \times 6$ matrix in the camera. (C) A typical thermal camera image of the membrane, where darker fields correspond to higher temperature. The thermal image is averaged in a $10 \times 10$ matrix, and the central $6 \times 6$ matrix is averaged to provide a measure of the temperature rise $\Delta \mathrm{T}$ due to reaction.

\section{Results and Discussion}

TEM images of the titania supported gold catalyst (supplementary information) are similar to those obtained previously in high throughput electrocatalytic measurements of the same catalyst system. ${ }^{19}$ These have been used to obtain the particle size dependence of supported gold as a function of the equivalent coverage of deposited gold. Nucleation and growth leads to particle size distributions, shown for three equivalent coverages of gold in Figure 3 , similar to that found previously.

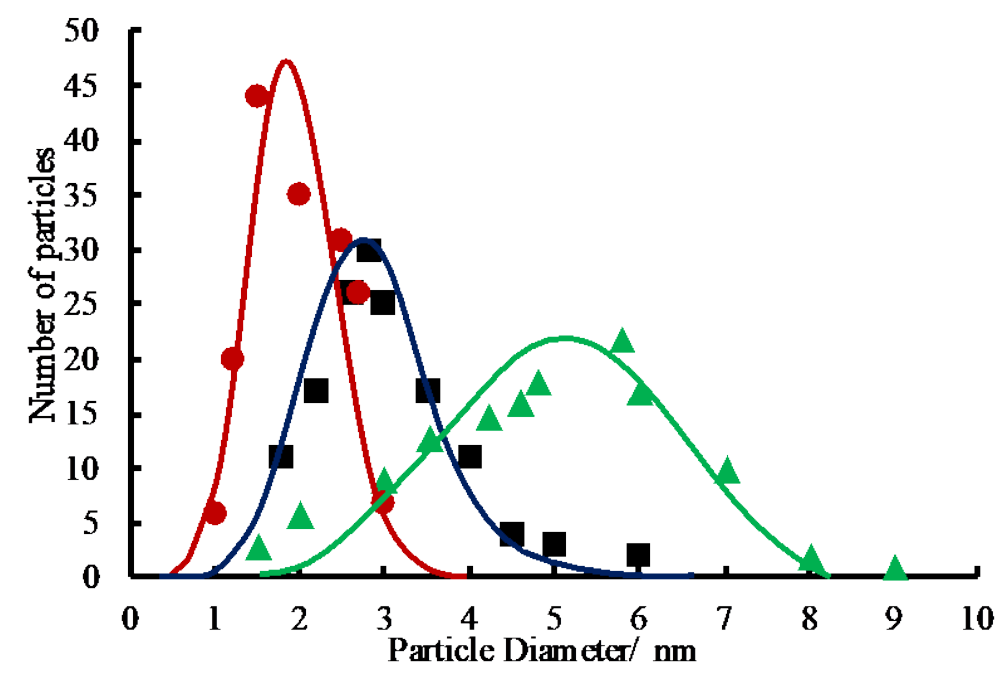

Figure $3 \mathrm{Au}$ nanoparticle size distributions at various deposition times (deposition rate $=0.15 \AA \mathrm{s}^{-1}$ ) determined for three equivalent thicknesses of gold from TEM images: circles $4.5 \AA$ (30s), squares $18 \AA$ (120s), triangles $45 \AA$ (300s). 
In order to establish that there was no significant change in the particle size distribution after the CO oxidation reaction (we were not able to measure the distributions directly on chip using TEM) XPS was carried out both before and after the reaction. Example XPS spectra are shown in the supplementary information. Figure 4 shows the dependence of the Au $4 f_{7 / 2}$ binding energy as a function of the gold particle size measured before and after the reaction on the supported gold catalysts on the screening chip. An upward shift in binding energy for decreasing particle size, as has been observed previously for particles grown under identical conditions on electrochemical screening chips. ${ }^{19}$ The shift is very similar to that found for $\mathrm{Au}$ particles supported on $\mathrm{TiO}_{2}(110)$ surfaces during the initial growth stages, and was associated with final state effects (electron screening in a small cluster) rather than any initial state effect. ${ }^{22-23}$ The measurements were made both before and after the $\mathrm{CO}$ oxidation reaction has taken place at $170^{\circ} \mathrm{C}$. Within experimental error, the binding energy of the gold has remained the same for each particle size, indicating that there was no significant change in particle size during reaction.

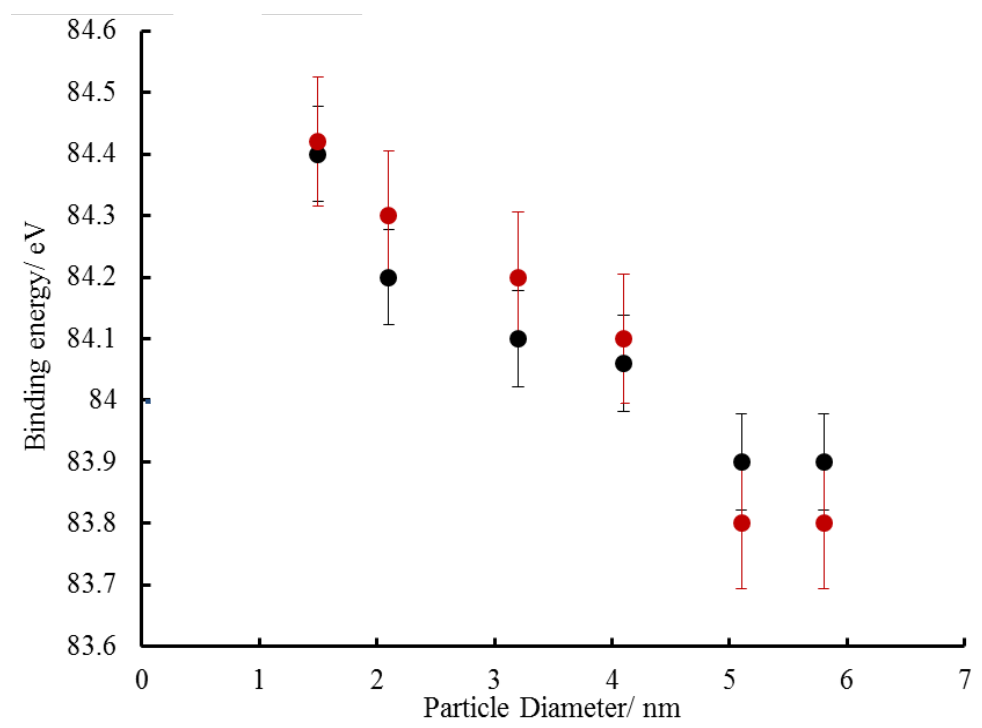

Figure 4 The Au 4f/2 binding energy measured in XPS of the titania supported gold particles as a function of particle size. The measurements have been made both before (red points) and after (black points) the $\mathrm{CO}$ oxidation reaction has taken place at $170^{\circ} \mathrm{C}$. Gold was deposited at a deposition rate of $0.15 \AA \mathrm{s}^{-1}$ onto amorphous titania at a substrate temperature of $250^{\circ} \mathrm{C}$.

A library of 100 titania supported gold catalyst on the chip membranes was heated to a base reaction temperature in the UHV chamber. The temperature variation across the chip at $300^{\circ} \mathrm{C}$ was less than $2 \%$. The temperature of the membrane was measured $\left(\mathrm{T}_{0}\right)$ after equilibrating with a pressure $P$ of pure oxygen in the chamber. The chamber was subsequently raised to the same total pressure $P$ of a set ratio of oxygen and carbon monoxide, and equilibrated before the temperature of the membrane during reaction $\left(T_{R}\right)$ was also measured. The measurement of the increase in catalyst temperatures $(\Delta T)$ was the average over a period of 5 minutes over the centre $6 \times 6$ matrix of the camera image (Figure 2C) at each membrane on the screening chip. The measurements were taken after equilibrating for 5 minutes in the oxygen / carbon monoxide environment. The change in temperature from the catalysed exothermic reaction $(\Delta T)$ was determined from the difference $T_{R}-T_{0}$. Figure $5 A$ shows the 
temperature change $\Delta \mathrm{T}$ at each of the 100 membrane supported catalysts resulting from the oxidation of the carbon monoxide. The base temperature of the catalysts was $170^{\circ} \mathrm{C}$, and the total pressure of the gas mixture was $1.5 \mathrm{mBar}$ with an $\mathrm{O}_{2}: \mathrm{CO}$ ratio of $1: 2$. The temperature was measured simultaneously on all the catalysts integrating over a 5-minuite interval. The catalysts were synthesised so that the particle sizes were constant across the rows, and varied in the columns (as indicated). Figure 5B plots the temperature rise (averaged over the ten catalysts with the same size particles) as a function of the mean particle size. There is clearly an increase in $\Delta T$ (a faster rate of reaction) as the gold particle size (and hence the effective thickness of gold) is reduced. The change in temperature across a row of the same particle sizes is ca. $0.2^{\circ} \mathrm{C}$ (much smaller than the changes in the columns) and could be associated with a partial shielding of the gas flux at the edges of the sample by the holder.
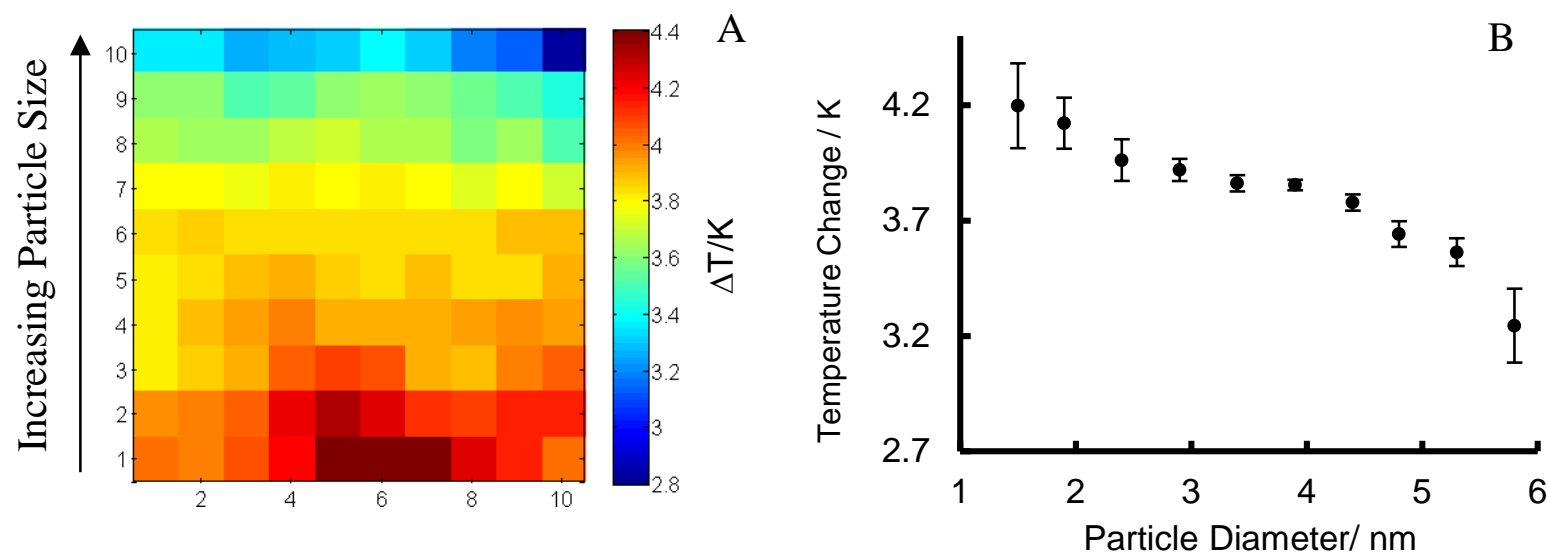

Figure $5 \mathrm{~A}$ ) The temperature change $\Delta \mathrm{T}$ (shown in false colour) due to the $\mathrm{CO}$ oxidation reaction on an array of $100 \mathrm{Au} / \mathrm{TiO}_{2}$ catalysts at $170^{\circ} \mathrm{C}$ measured simultaneously with the infra-red camera. The IR measurement was averaged over a 5-minute interval. The total pressure of the gas mixture was $1.5 \mathrm{mBar}$ and the $\mathrm{O}_{2}: \mathrm{CO}$ ratio was 1:2. The particle size on each of the rows is constant, and changes (from $1.5 \mathrm{~nm}$ to $6 \mathrm{~nm}$ diameter) in the vertical columns. B) The average temperature rise $\Delta T$ over the ten catalysts with identical particle sizes: The errors represent the standard deviation in the 10 measurements.

The average temperature rise $\Delta \mathrm{T}$ is used to calculate the conversion rate of $\mathrm{CO}$ to $\mathrm{CO}_{2}$ at the catalyst assuming the enthalpy of reaction is $\Delta \mathrm{H}=-283 \mathrm{kJmol}^{-1}$. ${ }^{21}$ The mass of gold and the number of gold atoms at the surface of the particles per area of catalyst is calculated from the TEM images, assuming the particles are hemispherical. ${ }^{13,19,24}$ This allows the calculation of the turn over frequency (TOF) at the Au surface. Figure 6 is a plot of the TOF for the CO oxidation reaction at $80^{\circ} \mathrm{C}$ at pressures ranging from $8 \times 10^{-2}$ to $9 \times 10^{-1} \mathrm{mBar}$, with an $\mathrm{O}_{2}$ : $\mathrm{CO}$ ratio of $1: 1$. Under these reaction conditions, there is a monotonic increase in the TOF for decreasing particle sizeall pressures. In addition, an increase in pressure results in a higher rate of reaction, although the increase in rate with pressure is not linear. Figure 7 is a plot of the TOF for the $\mathrm{CO}$ oxidation reaction at $170^{\circ} \mathrm{C}$ at pressures ranging from $9 \times 10^{-2}$ to $1.5 \mathrm{mBar}$, with an $\mathrm{O}_{2}: \mathrm{CO}$ ratio of 1:2. Once again, under these reaction conditions there is a monotonic 
increase in the TOF with decreasing particle size. Increasing pressure, however, indicates that there is a limiting rate of reaction at the higher pressures.

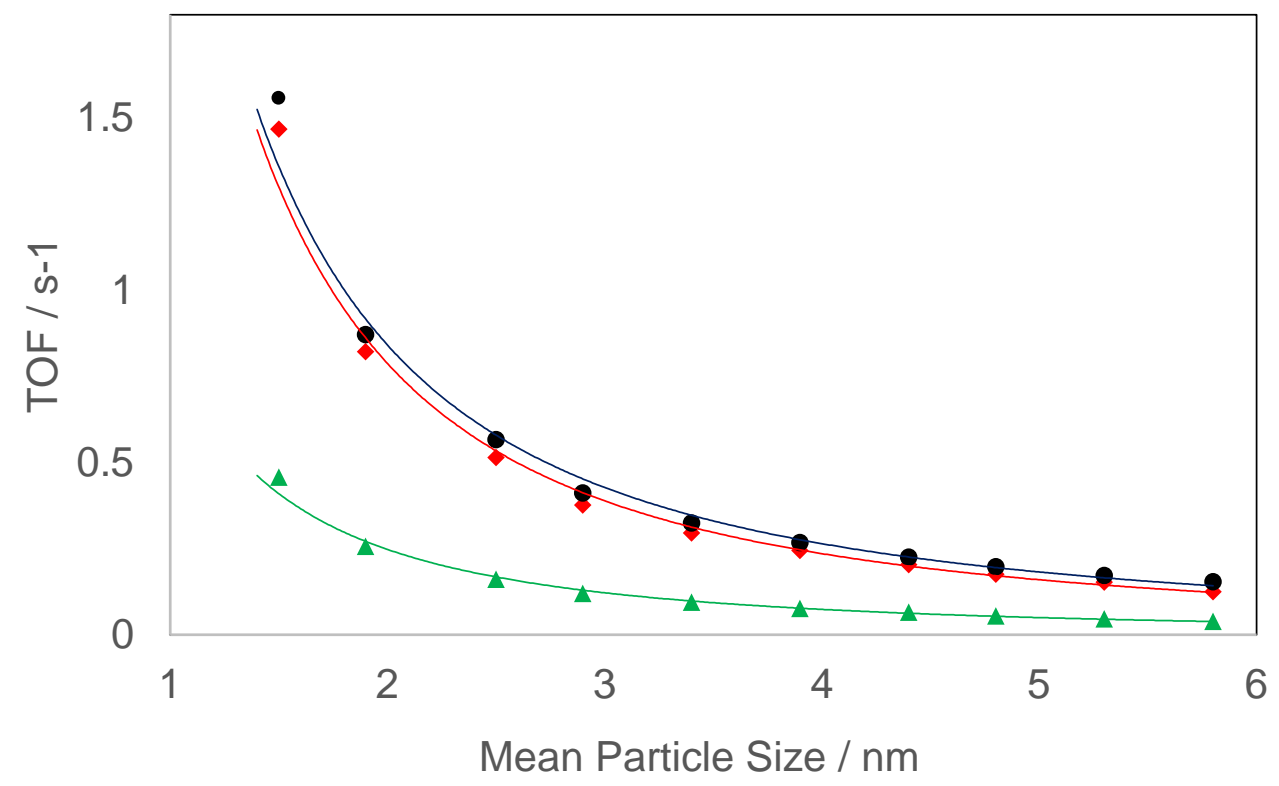

Figure 6 The TOF for the $\mathrm{CO}$ oxidation reaction on titania supported gold particles. The reaction temperature was $80^{\circ} \mathrm{C}$ and the $\mathrm{O}_{2}: \mathrm{CO}$ ratio was $1: 1$. Results are shown for total pressures of $8 \times 10^{-}$

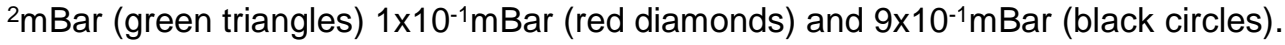

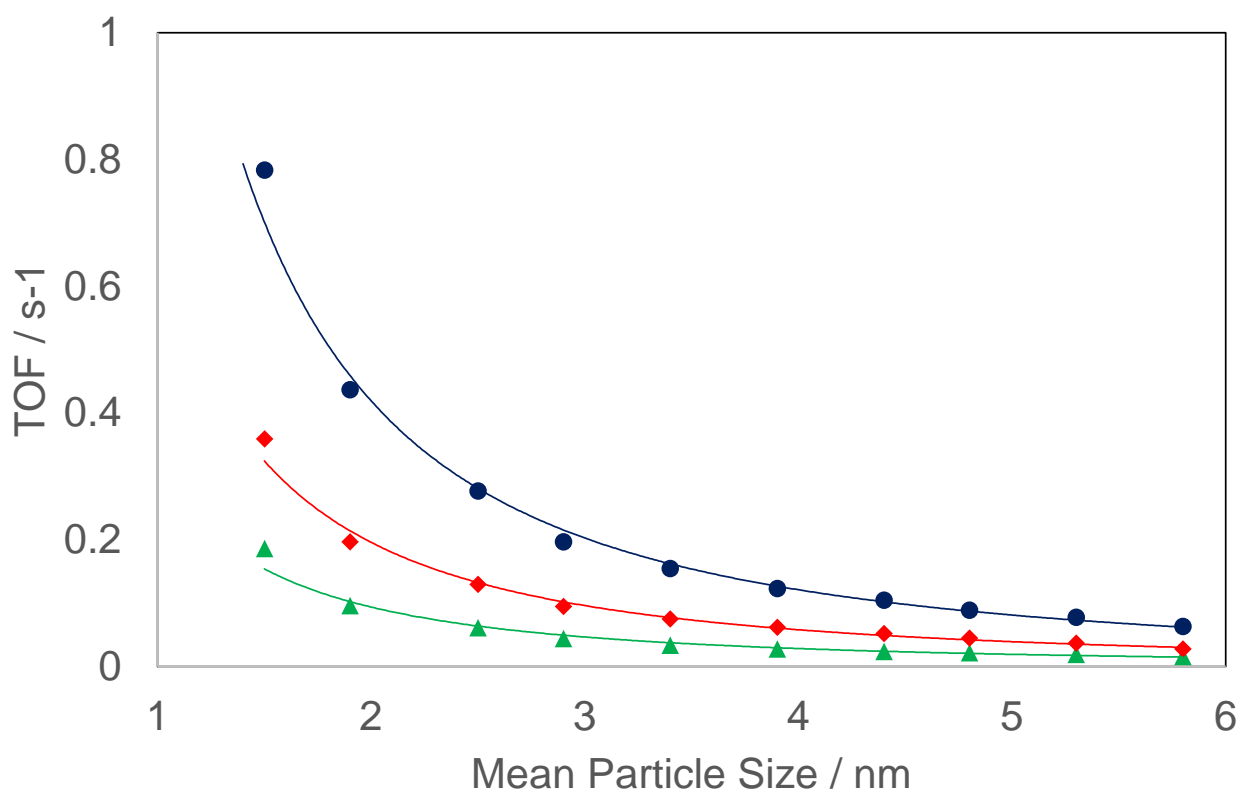

Figure 7 The TOF for the $\mathrm{CO}$ oxidation reaction on titania supported gold particles. The reaction temperature was $170^{\circ} \mathrm{C}$ and the $\mathrm{O}_{2}: \mathrm{CO}$ ratio was $1: 2$. Results are shown for total pressures of $9 \times 10^{-}$ ${ }^{2} \mathrm{mBar}$ (green triangle) $9 \times 10^{-1} \mathrm{mBar}$ (red diamond) and 1.5mBar (black circles). 
Under all the reaction conditions studied here, an increase in reaction rate with decreasing particle size is always observed. The monotonic increase in the TOF for CO oxidation on titania supported Au we observe here is consistent with observations made previously on high area titania supported catalysts down to ca. $3 \mathrm{~nm}$ diameter particles, ${ }^{6-7}$ and $2 \mathrm{~nm}$ particles ${ }^{8}$. We do not observe a maximum in the particle size dependence at around $3 \mathrm{~nm}$ observed elsewhere. ${ }^{9-10}$ At $80^{\circ} \mathrm{C}$ and a $\mathrm{CO}: \mathrm{O}_{2}$ ratio of $1: 1$ (Figure 6), with a total pressure of $8.4 \times 10^{-2}$ mbar the TOF increased from $0.016 \mathrm{~s}^{-1}$ for an Au particle size of $5.8 \mathrm{~nm}$, to $0.186 \mathrm{~s}^{-1}$ for $\mathrm{Au}$ particle size of $1.5 \mathrm{~nm}$, an increase in activity by a factor of $x 19 .{ }^{8}$ A slightly lower increase in activity of $\times 10$ was observed for similar conditions over the same particle size difference. There is an increase in the rate observed as one increases the reaction temperature, for a constant particle size and gas pressure, as one may expect. For a total pressure of $9 \times 10^{-1} \mathrm{mbar}$, a $\mathrm{O}_{2}: \mathrm{CO}$ ratio of $1: 2$ and a particle size of $1.5 \mathrm{~nm}$ the rate increases from $0.783 \mathrm{~s}^{-1}$ at $80^{\circ} \mathrm{C}$ to $1.558 \mathrm{~s}^{-1}$ at $170^{\circ} \mathrm{C}$, a factor of ca. $\mathrm{x} 2$ and similar to that found elsewhere. ${ }^{8}$ The increase in rate observed here with reducing particle size under all of the conditions investigated is found to be proportional to ca. $d^{-1.8}$ (curves fitted to data in Figure 6 and Figure 7).

The result can be considered in the light of the numerous active sites suggested to account for the low temperature CO oxidation activity of titania supported gold. These broadly fall into three categories: The active site is associated with the periphery of the gold particle on the support, high activity (low co-ordinate) gold sites on the nano-particle, and electronic modification of gold nano-particles by the substrate.

Activity at sites at the periphery of the gold nano-particles was indeed suggested to explain the early experimental studies on high area catalysts ${ }^{25-26}$ and this model was subsequently supported by the predictions of ab-initio calculations for this system: Gold at the periphery of the particle strongly stabilises oxygen adsorbed on the titania substrate resulting in a very low activation barrier for the reaction with $\mathrm{CO}$ adsorbed at nearby gold sites. ${ }^{27-28}$ In order to explore this possibility, we have calculated the total particle circumference per surface area of the titania support from the TEM determined particle distributions, and plotted this against the mean particle size in Figure 8. Particles have been synthesised in a region of nucleation and growth which leads to a near constant density of particles $\left(1.9 \times 10^{12} \mathrm{~mm}^{-2}\right)$ in the catalysts. The result is that the circumference increases linearly with increasing mean particle size (Figure 8). It is reasonable to assume that the number of edge sites at the gold/titania interface is proportional to the circumference: There is clearly a strong decrease in the TOF (Figure 6 and 7) with the increasing density of these sites on the surface (Figure 8). The results presented here are therefore not consistent with a model where the active site for $\mathrm{CO}$ oxidation is at the periphery of the gold nano-particle.

Assuming that the gold particles are, to the first approximation, supported hemispheres, we have also calculated the total gold surface area per area of support (Figure 8). Not surprisingly, since the density of particles is constant, there is an increase in gold surface area proportional to $\mathrm{d}^{2}$. This represents a direct anti-correlation with the trend in observed (Figure 6 and Figure 7) in the activity ( $\mathrm{a} \mathrm{d}^{-1.8}$ dependence in the TOF) over the range of nano-particle sizes investigated. The result is that the net increase in specific catalytic activity per surface area of gold is increasing as a function of $\mathrm{d}^{-4}$. For example, the gold surface specific activity for a $2 \mathrm{~nm}$ particle is ca. $\times 215$ higher than for a $5 \mathrm{~nm}$ particle for a reaction temperature of $80^{\circ} \mathrm{C}, \mathrm{O}_{2}: \mathrm{CO}$ ratio of $1: 1$ and a total pressure of $9 \times 10^{-1} \mathrm{mBar}$ (Figure 6 ). This rate of increase in surface specific activity is considerably higher that the increase in rate one may expect from the 
increasing number of, for example, higher activity low co-ordinate edge sites in the particle: These increase as a proportion of the total gold sites in the nano-particle at a significantly lower rate with reduced particle size. ${ }^{12,29-32}$

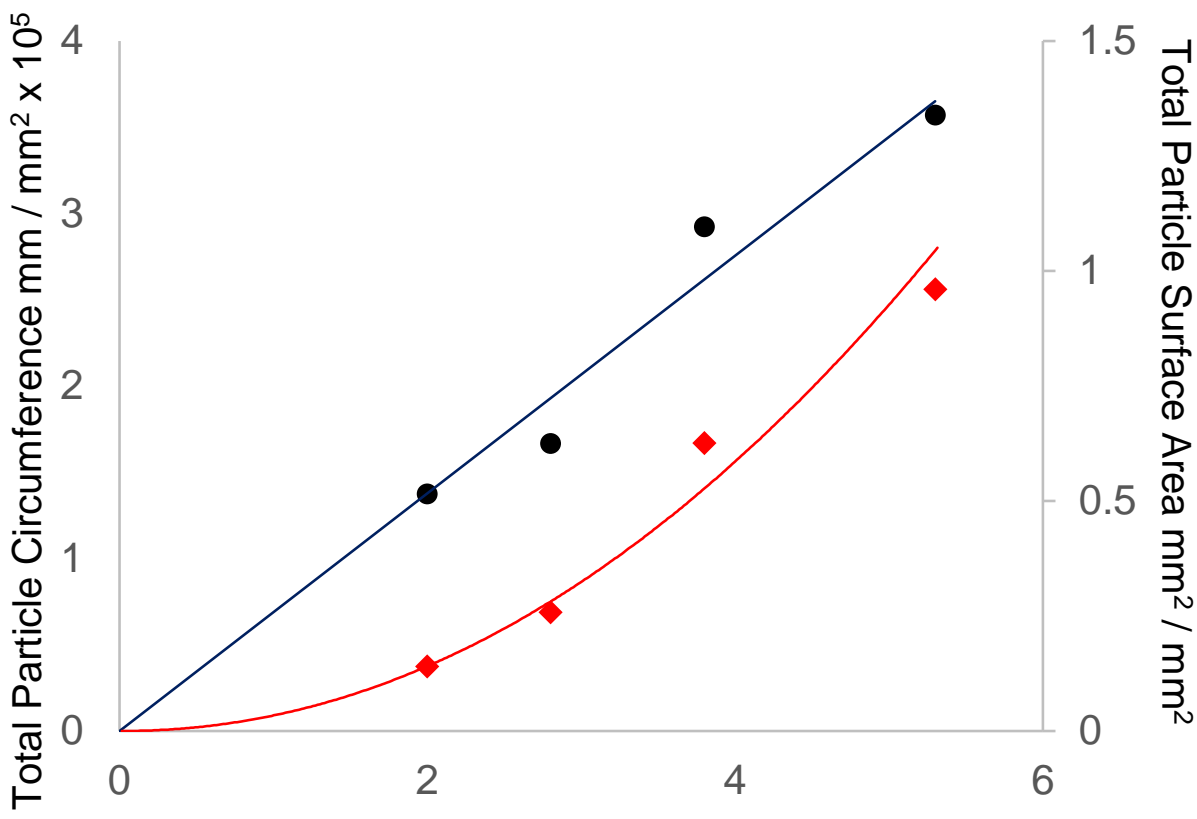

Mean Particle Size / nm

Figure 8 The total circumference $(\mathrm{mm})$ and surface area $\left(\mathrm{mm}^{2}\right)$ of particles (per $\mathrm{mm}^{2}$ of titania support) calculated from the TEM images of titania supported Au nanoparticles for the four different deposition times, (a) $30 \mathrm{sec}$, (b) $2 \mathrm{~min}$, (c) $3.5 \mathrm{~min}$ and (d) $5 \mathrm{~min}$ corresponding to a mean particle size of (a) 2.0 $\mathrm{nm}$, (b) $2.8 \mathrm{~nm}$, (c) $4.5 \mathrm{~nm}$ and (d) $5.3 \mathrm{~nm}$. Particles were deposited at an Au deposition rate of 0.15 $\AA / s$ and a substrate deposition temperature of $200^{\circ} \mathrm{C}$.

We suggest, therefore, on the basis that the net increase in specific catalytic activity per surface area of gold is so sharply dependent on decreasing particle size ( $\mathrm{a} \mathrm{d}^{-4}$ dependence), that only a significant metal-support interaction can account for this steep increase. ${ }^{33-40}$ Of course this does not preclude the possibility that the highest $\mathrm{CO}$ oxidation rates are also at particular gold sites on the nano-particle.

Electro-oxidation of $\mathrm{CO}$ on supported gold nano-particles using high throughput screening provided evidence that gold supported on amorphous titania with the same range of particle sizes also exhibits high activity while carbon supported gold is much less active. ${ }^{13,17}$ Unlike the monotonic increase in $\mathrm{CO}$ oxidation activity observed here for gas phase reactants, an optimum activity is observed at a particle size of ca. $3 \mathrm{~nm}$. In the latter case the oxidant is water, via adsorbed $\mathrm{OH}$, rather than $\mathrm{O}_{2}$. It is also worthy to note that there are investigations of the heterogeneous reaction studied here also resulted in an optimal particle size of ca. 2.5$3 \mathrm{~nm} \cdot{ }^{9-11}$ In the light of evidence that residual water can strongly influence the activity of such catalysts towards $\mathrm{CO}$ oxidation, ${ }^{7,} 41-42$ it is possible that it also plays an important role in determining the particle size dependence of the reaction. It is, however, interesting that electro-catalytic activity induced in gold by titania was concluded to be a result of an electronic 
interaction between the gold and the support, rather than an intrinsic nano-particle size effect. ${ }^{43}$

\section{Conclusion}

A combinatorial synthetic method of creating a library of titania supported gold planar catalyst ${ }^{19}$ has been combined with a high-throughput thermographic screening method to determine the activity of an exothermic catalytic reaction. A silicon-based screening chip was designed and fabricated in order to produce multiple fields $(10 \times 10)$ of low stress silicon nitride membranes that exhibit low thermal conductivity and heat capacity. An amorphous titania support was subsequently synthesised on the membranes: Gold particles of varying size were then grown through nucleation and growth using an evaporative source to produce the library of 100 catalysts. The heat generated during an exothermic reaction on the supported model catalysts on the membranes was measured using a thermal (infra-red) imaging camera. The rise in temperature of the catalysts under steady state reaction conditions was used to calculate the turn over frequency (TOF) for the reaction.

The catalytic activity for $\mathrm{CO}$ oxidation of titania supported gold model catalysts with varying particle sizes in the range $6>\mathrm{d} / \mathrm{nm}>1.5$ has been measured on 100 catalysts simultaneously. The reaction has been investigated at $80^{\circ} \mathrm{C}$ and $170{ }^{\circ} \mathrm{C}$, and pressures ranging between 0.06 mbar and $1.5 \mathrm{mbar}$ for various $\mathrm{O}_{2}$ : CO ratios. We have shown using XPS before and after reaction that there is no significant change in the particle size during the catalytic oxidation reaction. Under all conditions investigated, a monotonic increase in the TOF is observed with decreasing particle diameter (d) which is proportional to ca. $1 / \mathrm{d}^{-1.8}$. Since the number of particles for these catalysts is constant, there is a linear increase in the number of peripheral atoms at the gold nano-particles with increasing size, suggesting that high activity at these sites is unlikely to be responsible for the particle size dependence of the activity. Since the area of the gold particles is shown to increases as $\mathrm{d}^{2}$, the surface area specific activity of the gold is increasing with reducing particle size as ca. $\mathrm{d}^{-4}$. This is a significantly higher rate of increase than would be expected by, low co-ordinate gold atoms in, for example, edge sites which could be responsible for higher activity. The results suggest that the steep rate increase in the surface specific activity of the gold (proportional to $\mathrm{d}^{-4}$ ) is likely to be associated with a significant electronic interaction between the substrate and nano-particle.

\section{Acknowledgement.}

The authors wish to acknowledge Mkwawa University College of Education and the World Bank in their support for Jovine Emmanuel. 


\section{References}

1. Bond, G. C.; Sermon, P. A.; Webb, G.; Buchanan, D. A.; Wells, P. B., Hydrogenation over Supported Gold Catalysts. Journal of the Chemical Society-Chemical Communications 1973, (13), 444-445.

2. Haruta, M.; Koboyashi, T.; Sano, H.; Yamada, N., Novel Gold Catalysts for the Oxidation of Carbon Monoxide at a Temperature far Below 0C. Chem. Lett. 1987, 405-408.

3. $\quad$ Cameron, D.; Holliday, R.; Thompson, D., Gold's future role in fuel cell systems. $J$. Power Sources 2003, 118 (1-2), 298-303.

4. Haruta, M., When Gold Is Not Noble: Catalysis by Nanoparticles. The Chemical Record 2003, 3, 75-87.

5. Lee, I.; Zaera, F., Catalytic oxidation of carbon monoxide at cryogenic temperatures. J. Catal. 2014, 319, 155-162.

6. Haruta, M.; Tsubota, S.; Kobayashi, T.; Kageyama, H.; Genet, M. J.; Delmon, B., Low- Temperature oxidation of Co over Gold Supported on TiO2, FeO3, and CoO4. J. Catal. 1993, 144, 175-192.

7. Haruta, M., Nanoparticulate gold catalysts for low-temperature CO oxidation. J. New Mat.Electrochem. Syst. 2004, 7 (3), 163-172.

8. Herranz, T.; Deng, X. Y.; Cabot, A.; Alivisatos, P.; Liu, Z.; Soler-Illia, G.; Salmeron, M., Reactivity of Au nanoparticles supported over $\mathrm{SiO} 2$ and $\mathrm{TiO} 2$ studied by ambient pressure photoelectron spectroscopy. Catal. Today 2009, 143 (1-2), 158-166.

9. Bamwenda, G. R.; Tsubota, S.; Nakamura, T.; Haruta, M., The influence of the preparation methods on the catalytic activity of platinum and gold supported on $\mathrm{TiO} 2$ for $\mathrm{CO}$ oxidation. Catal. Lett. 1997, 44 (1-2), 83-87.

10. Valden, M.; Lai, X.; Goodman, D. W., Onset of catalytic activity of gold clusters on titania with the appearance of nonmetallic properties. Science 1998, 281 (5383), 1647-1650.

11. Laoufi, I.; Saint-Lager, M. C.; Lazzari, R.; Jupille, J.; Robach, O.; Garaudee, S.;

Cabailh, G.; Dolle, P.; Cruguel, H.; Bailly, A., Size and Catalytic Activity of Supported Gold Nanoparticles: An in Operando Study during CO Oxidation. J. Phys. Chem. C 2011, 115 (11), 4673-4679.

12. Min, B. K.; Friend, C. M., Heterogeneous gold-based catalysis for green chemistry: Low-temperature CO oxidation and propene oxidation. Chem. Rev. 2007, 107 (6), 27092724.

13. Hayden, B. E.; Pletcher, D.; Suchsland, J. P., Enhanced activity for electrocatalytic oxidation of carbon monoxide on titania-supported gold nanoparticles. Angew. Chem.-Int. Edit. 2007, 46 (19), 3530-3532.

14. Kondratyuk, P.; Gumuslu, G.; Shukla, S.; Miller, J. B.; Morreale, B. D.; Gellman, A. J., A microreactor array for spatially resolved measurement of catalytic activity for highthroughput catalysis science. J. Catal. 2013, 300 (0), 55-62.

15. Moates, F. C.; Somani, M.; Annamalai, J.; Richardson, J. T.; Luss, D.; Willson, R. C., Infrared thermographic screening of combinatorial libraries of heterogeneous catalysts. Ind. Eng. Chem. Res. 1996, 35 (12), 4801-4803.

16. Holzwarth, A.; Schmidt, P. W.; Maier, W. E., Detection of catalytic activity in combinatorial libraries of heterogeneous catalysts by IR thermography. Angew. Chem.-Int. Edit. 1998, 37 (19), 2644-2647.

17. Hayden, B. E., Particle Size and Support Effects in Electrocatalysis. Accounts Chem. Res. 2013, 46 (8), 1858-1866.

18. Guerin, S.; Hayden, B. E., Physical vapor deposition method for the high-throughput synthesis of solid-state material libraries. J. Comb. Chem. 2006, 8 (1), 66-73. 
19. Guerin, S.; Hayden, B. E.; Pletcher, D.; Rendall, M. E.; Suchsland, J. P.; Williams, L. J., Combinatorial approach to the study of particle size effects in electrocatalysis: Synthesis of supported gold nanoparticles. J. Comb. Chem. 2006, 8 (5), 791-798.

20. Anastasopoulos, A.; Davies, J. C.; Hannah, L.; Hayden, B. E.; Lee, C. E.; Milhano, C.; Mormiche, C.; Offin, L., The Particle Size Dependence of the Oxygen Reduction Reaction for Carbon-Supported Platinum and Palladium. Chemsuschem 2013, 6 (10), 19731982.

21. Price, G., Thermodynamics of Chemical Processes. Oxford University Press New York, 1998.

22. Zhang, L.; Persaud, R.; Madey, T. E., Ultrathin metal films on a metal oxide surface: Growth of Au on TiO2 (110). Phys. Rev. B 1997, 56 (16), 10549-10557.

23. Howard, A.; Clark, D. N. S.; Mitchell, C. E. J.; Egdell, R. G.; Dhanak, V. R., Initial and final state effects in photoemission from Au nanoclusters on $\mathrm{TiO}_{2}\left(\begin{array}{ll}1 & 1\end{array}\right)$. Surf. Sci. 2002, 518 (3), 210-224.

24. Hayden, B. E.; Pletcher, D.; Rendall, M. E.; Suchsland, J. P., CO oxidation on gold in acidic environments: Particle size and substrate effects. J. Phys. Chem. C 2007, 111 (45), 17044-17051.

25. Haruta, M., Size- and support-dependency in the catalysis of gold. Catal. Today 1997, 36 (1), 153-166.

26. Haruta, M.; Uphade, B. S.; Tsubota, S.; Miyamoto, A., Selective oxidation of propylene over gold deposited on titanium-based oxides. Research on Chemical Intermediates 1998, 24 (3), 329-336.

27. Liu, Z. P.; Gong, X. Q.; Kohanoff, J.; Sanchez, C.; Hu, P., Catalytic role of metal oxides in gold-based catalysts: A first principles study of CO oxidation on TiO2 supported Au. Phys. Rev. Lett. 2003, 91 (26).

28. Molina, L. M.; Rasmussen, M. D.; Hammer, B., Adsorption of O-2 and oxidation of $\mathrm{CO}$ at Au nanoparticles supported by TiO2(110). Journal of Chemical Physics 2004, 120 (16), 7673-7680.

29. Lopez, N.; Janssens, T. V. W.; Clausen, B. S.; Xu, Y.; Mavrikakis, M.; Bligaard, T.; Norskov, J. K., On the origin of the catalytic activity of gold nanoparticles for lowtemperature CO oxidation. J. Catal. 2004, 223 (1), 232-235.

30. Hvolbaek, B.; Janssens, T. V. W.; Clausen, B. S.; Falsig, H.; Christensen, C. H.; Norskov, J. K., Catalytic activity of Au nanoparticles. Nano Today 2007, 2 (4), 14-18.

31. Hussain, A.; Muller, A. J.; Nieuwenhuys, B. E.; Gracia, J. M.; Niemantsverdriet, J. W., Two Gold Surfaces and a Cluster with Remarkable Reactivity for CO Oxidation, a Density Functional Theory Study. Top. Catal. 2011, 54 (5-7), 415-423.

32. Wang, S. W.; Omidvar, N.; Marx, E.; Xin, H. L., Coordination numbers for unraveling intrinsic size effects in gold-catalyzed CO oxidation. Phys. Chem. Chem. Phys. 2018, 20 (9), 6055-6059.

33. Prestianni, A.; Martorana, A.; Ciofini, I.; Labat, F.; Adamo, C., CO Oxidation on Cationic Gold Clusters: A Theoretical Study. J. Phys. Chem. C 2008, 112 (46), 18061-18066. 34. Chen, M. S.; Goodman, D. W., The Structure of Catalytically Active Gold on Titania. Science 2004, 306, 252-255.

35. Chen, M. S.; Goodman, D. W., Structure-activity relationships in supported Au catalysts. Catal. Today 2006, 111 (1-2), 22-33.

36. Wahlström, E.; Lopez, N.; Schaub, R.; Thostrup, P.; Ronnau, A.; Africh, C.; Laegsgaard, E.; Nørskov, J. K.; Besenbacher, F., Bonding of Gold Nanoclusters to Oxygen Vacancies on Rutile $\mathrm{TiO}_{2}$ (110). Phys. Rev. Lett. 2003, 90 (2), 026101.

37. Vijay, A.; Mills, G.; Metiu, H., Adsorption of gold on stoichiometric and reduced rutile $\mathrm{TiO}_{2}$ (110) surfaces. Journal of Chemical Physics 2003, 118 (14), 6536-6551. 
38. Wang, Y.; Hwang, G. S., Adsorption of Au atoms on stoichiometric and reduced $\mathrm{TiO}_{2}(110)$ rutile surfaces: a first principles study. Surf. Sci. 2003, 542 (1-2), 72-80.

39. Vittadini, A.; Selloni, A., Small gold clusters on stoichiometric and defected TiO[sub 2] anatase (101) and their interaction with CO: A density functional study. The Journal of Chemical Physics 2002, 117 (1), 353-361.

40. $\quad$ Okazaki, K.; Morikawa, Y.; Tanaka, S.; Tanaka, K.; Kohyama, M., Effects of stoichiometry on electronic states of Au and Pt supported on $\mathrm{TiO}_{2}(110)$. J. Mater. Sci. 2005, 40 (12), 3075-3080.

41. Boccuzzi, F.; Chiorino, A.; Manzoli, M.; Lu, P.; Akita, T.; Ichikawa, S.; Haruta, M., $\mathrm{Au} / \mathrm{TiO} 2$ nanosized samples: A catalytic, TEM, and FTIR study of the effect of calcination temperature on the CO oxidation. J. Catal. 2001, 202 (2), 256-267.

42. Kung, H. H.; Kung, M. C.; Costello, C. K., Supported Au catalysts for low temperature CO oxidation. J. Catal. 2003, 216 (1-2), 425-432.

43. Rodriguez, P.; Plana, D.; Fermin, D. J.; Koper, M. T. M., New insights into the catalytic activity of gold nanoparticles for CO oxidation in electrochemical media. J. Catal. 2014, 311, 182-189. 